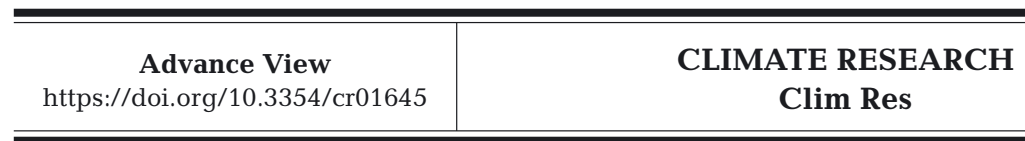

Contribution to CR Special 'Sustainable management of renewable resources in a changing environment: an integrated approach across terrestrial, freshwater and marine ecosystems'

\title{
Low impact of first-time spawners on population growth in a brown trout population
}

\author{
Marlene Wæge Stubberud ${ }^{1, *}$, Chloé R. Nater ${ }^{1,2}$, Yngvild Vindenes ${ }^{1}$, \\ L. Asbjørn Vøllestad ${ }^{1}$, Øystein Langangen ${ }^{1}$
}

\author{
${ }^{1}$ Department of Biosciences, University of Oslo, 0316 Oslo, Norway \\ ${ }^{2}$ Centre for Biodiversity Dynamics (CBD), Norwegian University of Science and Technology, 7491 Trondheim, Norway
}

\begin{abstract}
For species with individual variation in reproductive success, experience in breeding and the distribution of different breeders is important for population productivity and viability. Human impacts, such as climate change and harvesting, can alter this distribution and thus population dynamics. Here, we investigated the effect of spawning experience on population growth in a population of migratory brown trout Salmo trutta subject to stressors including migration barriers, harvesting, and climate change. We described the population dynamics with a structured integral projection model that differentiates between first-time and repeat spawners. We then took a scenario-based approach to test to which extent spawning experience has a positive effect on the population growth of brown trout by running 3 different model simulations: a baseline scenario with no changes to the reproductive output of the population, a non-selective scenario in which the reproductive output of all spawners was reduced, and a selective scenario where the reproductive output of only first-time spawners was reduced. We found that the reproductive output of repeat spawners is more important than that of first-time spawners for population growth, in line with other studies. Moreover, the contribution of first-time spawners to the population growth through their own survival is more important than their contribution to growth through reproduction. To ensure the continued existence of the study population, survival of first-time spawners and reproductive success of repeat spawners should be prioritised. More generally, including breeding experience adds more mechanistic detail, which ultimately can aid management and conservation efforts.
\end{abstract}

KEY WORDS: Integral projection model - Iteroparity - Spawning experience - Management · Selective harvesting $\cdot$ Population dynamics $\cdot$ Brown trout $\cdot$ Salmo trutta $\cdot$ Dam

\section{INTRODUCTION}

Populations are made up of individuals that differ genetically, physically, and in acquired skills and knowledge. For species that reproduce more than once, i.e. iteroparous species, the distribution of individuals with different experience in breeding can influence the population dynamics. For animals, reproductive success often increases with experience (e.g. Weimerskirch \& Jouventin 1987, Carr \& Kaufman 2009, Zedrosser et al. 2009), and the dis-

${ }^{*}$ Corresponding author: m.w.stubberud@ibv.uio.no tributions of inexperienced and experienced breeders in a population can explain a substantial part of the variation in reproductive output (Wigley 1999). Human activities can alter the distributions of different types of breeders within populations, for instance through climate change, habitat changes, and harvesting. To study the potential effects of human impacts on reproductive output and longterm population growth rate in iteroparous species, we need model frameworks that explicitly include breeding experience. 
Body size is a key trait for vital rates, particularly reproduction. For example, in species with indeterminate growth such as long-lived fish in colder regions, body and gonad mass is generally positively correlated, and larger females produce more eggs (Jonsson 1978, Trippel 1998). Given this relationship, it is common to estimate the annual reproductive output of a fish population based on its spawning stock biomass. As a result, fecundity is often assumed to only scale with body mass, but the relationship is rarely that straightforward (Subbey et al. 2014). Eggs produced by larger females are more plentiful, but also often bigger and of higher quality than those of smaller females (Monteleone \& Houde 1990, Jonsson \& Jonsson 1999). In turn, egg size and quality influence fertilisation rate, hatching probabilities, and early survival (Daniel et al. 1993, Solemdal et al. 1995, Berkeley et al. 2004). Thus, the contribution of several small females might not be equal to the contribution of fewer large females, even though they have the same total body mass.

Several experimental and observational studies have found that the number and quality of offspring are correlated with maternal age as well as body size (e.g. Marteinsdóttir \& Begg 2002, Sogard et al. 2008, Venturelli et al. 2009). Therefore, the precision of the reproductive output estimate can increase if the size and/or age distribution is included (Wigley 1999). Moreover, there is often large among-individual variation in age at maturity, egg production, and early survival irrespective of size (e.g. Carr \& Kaufman 2009, Marshall 2009, Óskarsson \& Taggart 2010), indicating that additional traits affect fertility. In iteroparous species, breeding experience is known to influence reproductive output (Woolfenden \& Fitzpatrick 1984, Komdeur 1996, Snowdon 1996). As the main improvement typically occurs from the first to the second breeding attempt, it is common to distinguish between first-time and repeat breeders (Hislop 1988, Künkele 2000, Zedrosser et al. 2009). Repeat breeders have higher reproductive success since they tend to have better timing (Kjesbu et al. 1996, Óskarsson \& Taggart 2010), higher social status, and improved skills, e.g. nest building in birds and fish (Greeley 1932, Potts et al. 1980, Curio 1983).

In both Atlantic cod Gadus morhua (Carr \& Kaufman 2009) and Atlantic herring Clupea harengus (Óskarsson \& Taggart 2010), the reproductive output of first-time spawners was found to be inferior, or even insignificant, relative to that of repeat spawners. Although the reproductive output from first-time breeders can be trivial for population growth, the survival of first-time spawners to become repeat spawners is not. If the mortality of first-time breeders increases, there will be fewer future repeat breeders and potentially fewer juveniles produced, which could lead to a population decrease (e.g. Mumme et al. 2000). Harvest yields measured by weight can also decrease with increasing first-time spawner mortality, as first-time spawners contribute with their own growth (Edwards \& Plagányi 2011). Repeat spawning fish usually invest more in gamete production regardless of their size and energy consumption both in marine fish (e.g. Atlantic halibut Hippoglossus hippoglossus, Evans et al. 1996) and in long-lived freshwater fish such as iteroparous migratory salmonids (e.g. brown trout Salmo trutta, Jonsson 1985).

For migratory populations that move between feeding and breeding grounds, river regulation, harvesting, and other human impacts can affect the distribution of spawners, and thus the population dynamics (e.g. Ohlberger et al. 2020). The precision of reproductive output and other population estimates in iteroparous species is likely to improve if breeding experience is included (Carr \& Kaufman 2009, Óskarsson \& Taggart 2010), e.g. the proportion of first-time to repeat spawners in the population (Wigley 1999, Lawrence et al. 2016, Bordeleau et al. 2020). In combination with selective harvest, directional environmental changes, such as climate change, can lead to extinction in otherwise viable populations (Knell \& Martínez-Ruiz 2017). Harvested freshwater species, including many salmonids, are of particular concern, since climate change increases temperatures and alters water flow in freshwater ecosystems (e.g. Rand et al. 2006). The increased temperature could be especially problematic for species adapted to colder regions, such as trout (Kovach et al. 2016, Muhlfeld et al. 2018).

Structured population models, such as matrix models or integral projection models (IPMs), are useful tools for exploring the dynamical consequences of various human-induced impacts such as harvesting, climate change, or habitat degradation, without putting any real population at risk. IPMs and matrix models belong to the same model class, and share the same analytical properties. Matrix models use discrete stages, while IPMs also include continuous states such as size (Easterling et al. 2000). IPMs are thus models that provide a natural framework for investigating the dynamics of populations that are structured both by body size and additional discrete traits such as breeding experience.

Here, we use an IPM to investigate the role of firsttime and repeat spawners for population growth and dynamics in a population of landlocked, i.e. adfluvial, 
brown trout. The IPM developed by Nater et al. (2021, this issue) for the same population is extended here to explicitly include first-time and repeat spawning stages. The study population is harvested extensively, and spawns in a regulated river with a hydropower dam located in the middle of its main spawning area (Aass et al. 1989, Aass \& Kraabøl 1999). Spawning location relative to the dam is accounted for in the IPM, along with main life cycle stages and body size. Nater et al. (2018) investigated the effects of 2 climate-related variables (mean river temperature and waterflow) on somatic growth, and found that neither explained much of the variation observed in the population, and that both were dwarfed by residual among-year and individual variation. Given these results from our study system, and results from studies of other iteroparous fish species (e.g. Carr \& Kaufman 2009, Óskarsson \& Taggart 2010, Lawrence et al. 2016, Bordeleau et al. 2020), we hypothesised that reproductive output increases with spawning experience in brown trout, and that the survival of first-time spawners to become repeat spawners is more important for the long-term population growth rate than their reproductive contribution. To test this hypothesis, we ran and compared several model scenarios: (1) a baseline scenario without reduced reproductive output, (2) a non-selective perturbation scenario where the reproductive output of all spawners is reduced, and (3) a selective perturbation scenario where the reproductive output of first-time spawners is reduced. In the 2 perturbed scenarios, the reproductive output of the spawners was reduced by decreasing early survival, a parameter that is expected to vary with both maternal spawning experience and environmental factors (e.g. Jonsson 1985, Elliott 1994). We also investigated the effects of adding harvest mortality in the different scenarios. To evaluate the impacts at the population level and to quantify the distribution of first-time and repeat spawners, we calculated long-term population growth rate and stable population structure.

\section{METHODS}

\subsection{Study system and data}

Our study population is known as the Hunder trout, a population of large brown trout in south-eastern Norway that has been harvested for centuries (Aass \& Kraabøl 1999). These fish inhabit the largest lake in Norway, Lake Mjøsa, which has a surface area of $365 \mathrm{~km}^{2}$ and maximum depth of $449 \mathrm{~m}$ (Aass et al. 1989). The Hunder trout spawn in the lower regions of the main inlet river, the $200 \mathrm{~km}$ long Gudbrandsdalslågen. The main spawning areas are located above and below the Hunderfossen waterfall, approximately $15 \mathrm{~km}$ from the lake. Since the 1960s, the waterfall has been regulated for hydropower production, and a dam divides the river. It is a run-ofriver facility, and the water is guided by the dam into a tunnel and through a turbine shaft before it reenters the river $4.4 \mathrm{~km}$ downstream (Fig. 1). This leaves the stretch between the dam and the tunnel outlet with low water levels much of the year, strongly restricting and impairing the spawning and nursery areas below the dam (Aass et al. 1989).

Hunder trout migrate between feeding grounds in the lake and spawning grounds in the river (Fig. 2). Even though this brown trout population is landlocked, it resembles anadromous populations of sea trout and Atlantic salmon Salmo salar both in life history and body size (Aass et al. 1989). Mature Hunder trout migrate upriver in late summer and early autumn, and large females typically arrive first at the spawning grounds (Jensen \& Aass 1995). After spawning, many migrate back to the lake to recondition, while some overwinter in the river and migrate downriver with the spring flood (Arnekleiv et al. 2007). The fertilised eggs overwinter in the gravel and hatch in the following spring. After emergence, the juveniles spend $3-5 \mathrm{yr}$ in the river before they smolt and migrate down to the lake at an average size of $250 \mathrm{~mm}$. After 2-4 yr in the lake, they mature at an average size of $630 \mathrm{~mm}$, and migrate back upriver as first-time spawners. Brown trout are iteroparous (Lobón-Cerviá \& Sanz 2017), and Hunder trout maintain a biennial spawning cycle whereby they alternate between spawning years and resting years (Aass et al. 1989).

As brown trout bury their eggs in the riverbed gravel, a reduced spawning area increases the chance of buried eggs being uncovered by subsequent females (Johnston et al. 2007), and low water levels leave the eggs at risk of drying out, freezing, or being scoured away by ice floes in spring (Aass et al. 1989, Harnish et al. 2014). To mitigate the negative impacts of the dam on reproduction, the population has been stocked with $15000-20000$ smolts ( 2 yr old) annually since the dam was constructed (Aass 1993). Prior to dam construction, the main spawning and harvest sites were below the waterfall (HuitfeldtKaas 1917). Numerous (presumably larger, Haugen et al. 2008) spawners ascended the waterfall before the dam was built. A large trout $(\sim 7 \mathrm{~kg}$ and $80-86)$ $\mathrm{cm}$ was caught and documented above the waterfall 


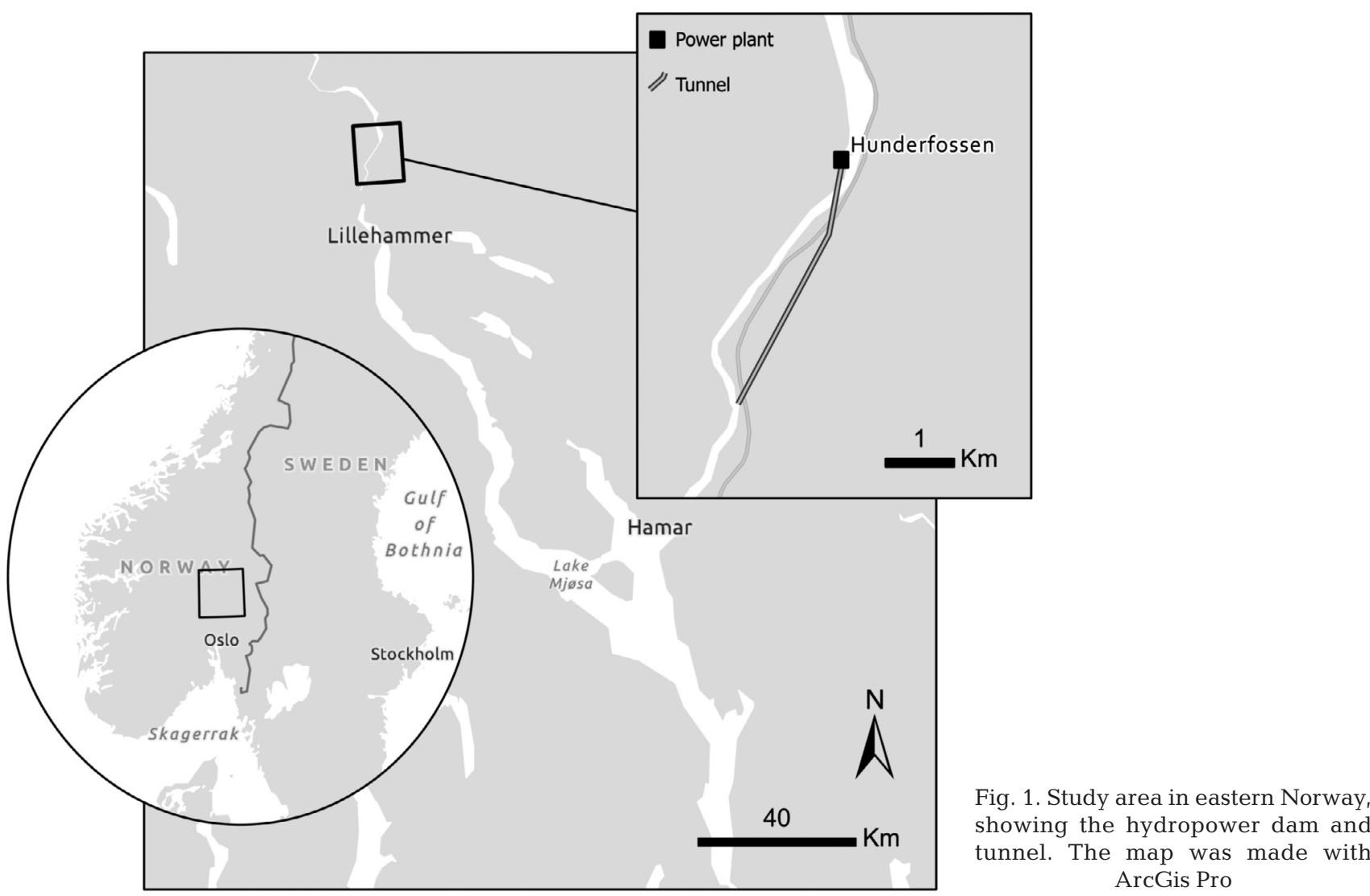

in 1780 (Huitfeldt-Kaas 1917), and there was an intense fishery with fixed wooden traps in the waterfall itself until the 1960s (Aass and Kraabøl 1999). As the dam is an absolute migration barrier, a 1-way fish ladder was opened in 1966 to facilitate upriver migration (Jensen \& Aass 1995). The fish ladder is selective, and mainly intermediate-sized spawners (normally distributed with mean $=657 \mathrm{~mm}$ and standard deviation $=132 \mathrm{~mm}$ ) have been caught in the ladder (Fig. 3A), leaving most of the larger trout to spawn below the dam (Haugen et al. 2008, Nater et al. 2021).

The Hunderfossen fish ladder includes a fish trap (Jensen \& Aass 1995), and all trout that ascended the ladder from 1966 to 2016 were captured, measured, and marked, while some were also sampled for scales. The resulting mark-recapture-recovery data include 15000 individual fish and 7000 individual scale samples. Using sclerochronological methods, the scale samples were translated into a large dataset of individual growth histories and smolting, maturation, and spawning schedules. Both datasets are described in more detail by Moe et al. (2020). These datasets were used to estimate the majority of the size-dependent vital rate relationships required to parameterise the model (for details, see Nater et al. 2021 and Section S1 [Vital rates] in Supplement 1 at www.int-res.com/articles/suppl/cr01645_supp1.pdf). We do not have data on the early life history in this study system, and used literature values (see Table S1 in Supplement 1). Size-dependent fecundity, i.e. the expected number of eggs given a female's body size, was estimated independently using a small sample of 15 females caught in the ladder and stripped in 2017 and 2018 (for details, see Nater et al. 2021 and Fig. S1 in Supplement 1).

\subsection{Structured IPM}

We extended the IPM developed by Nater et al. (2021) for the Hunder trout population to differentiate between first-time and repeat spawners. In a basic size-structured IPM, the population dynamics are described by 4 size-dependent vital rate functions: (1) annual survival probability, (2) next year's size distribution given current size, (3) number of juveniles that enter next year's population, and (4) the size distribution of juveniles, i.e. their initial size assignment (Easterling et al. 2000). In addition to size, the vital rates in our model depend on life history stage and location in the river relative to the hydropower dam (see Fig. S6 for the life cycle of Hunder trout with the dam). As repeat spawners 


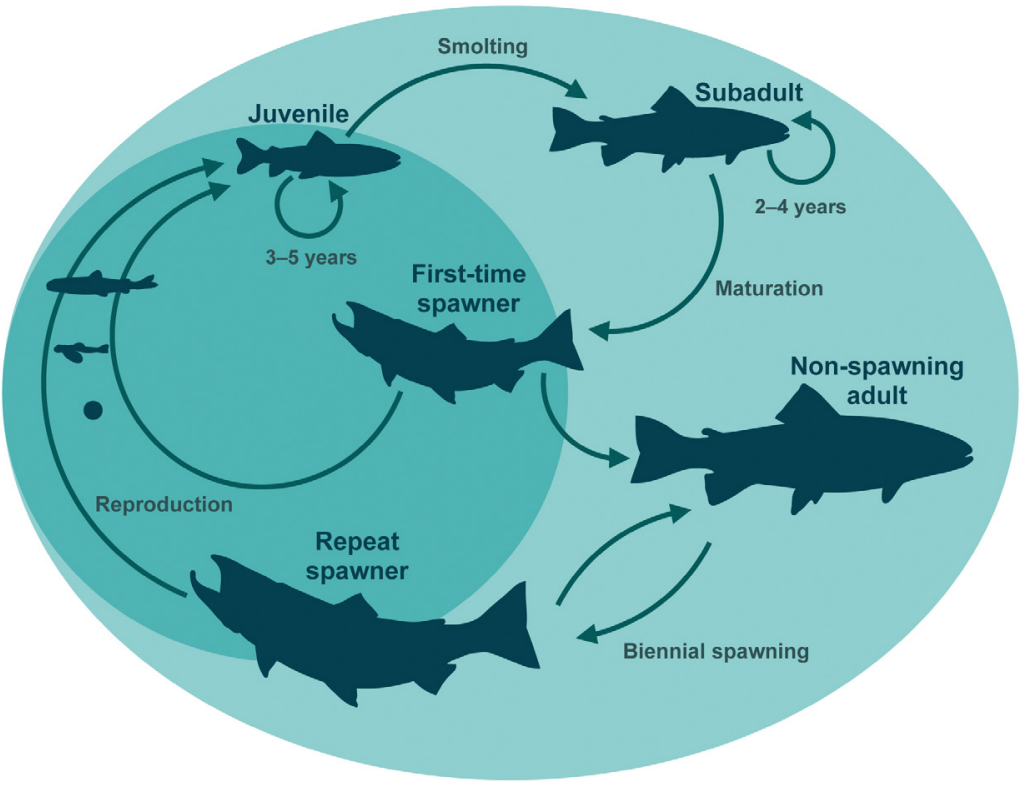

Fig. 2. Life cycle of the Hunder trout without the dam. The smaller circle to the left in the figure signifies the river stage of the life cycle. Fish represent life stages, all of which are size-structured, and arrows are possible transitions from year $t$ to $t+1$. All transitions are listed in Table 1

fish), and we used a pre-reproductive census so that the reproductive output is measured as the number of age-1 juveniles (i.e. it depends on the early first year survival). The estimates for background mortality of spawners below the dam are based on large individuals (Nater et al. 2020b) and are not reliable for smaller spawners. Hence, we used the subadult background mortality for the downriver first-time spawners (Table 1).

We denote size by $x$ (fork length, $\mathrm{mm}$ ) and location relative to the dam by $u$ for upriver, $d$ for downriver, and $z$ for either location. In the model, the year begins in late summer when the spawners enter the river. Each year, individuals grow from size $x$ to size $x^{\prime}$ in the next year. From one year to the next, individuals in life stage $j$ in year $t$ can contribute to life stage $i$ the next year $t+1$ (Fig. 2), and the different stages each consist of several cohorts.

become relatively fewer for each spawning event (Fig. 3B) and have quite similar vital rates, we grouped repeat spawners into a terminal group from the second spawning onwards (e.g. Engen et al. 2010, Bordeleau et al. 2020, but see Carr \& Kaufman 2009, who used more spawner groups). Although the population has been stocked since the 1960s, we used estimates for wild individuals (see Nater et al. 2021, where the stocked individuals are included). The model is density independent and female based (but see Stubberud et al. 2019 for a 2-sex IPM for
The number of individuals of size $x^{\prime}$ in stage $i$ at time $t+1$ is calculated by integrating, i.e. summing up, across all sizes and stages in the IPM (Ellner \& Rees 2006):

$$
N_{i}\left(x^{\prime}, t+1\right)=\sum_{j=1}^{\Omega} \int_{L}^{U} K_{i, j, z}\left(x^{\prime}, x\right) N_{j}(x, t) \mathrm{d} x
$$

where $N_{j}(x, t)$ is the number of individuals size $x$ in life stage $j$ at time $t, \Omega$ is the total number of life stages, and the range $[L, U]$ defines the lower and upper size limits, here $L=0$ and $U=1300 \mathrm{~mm}$ (see
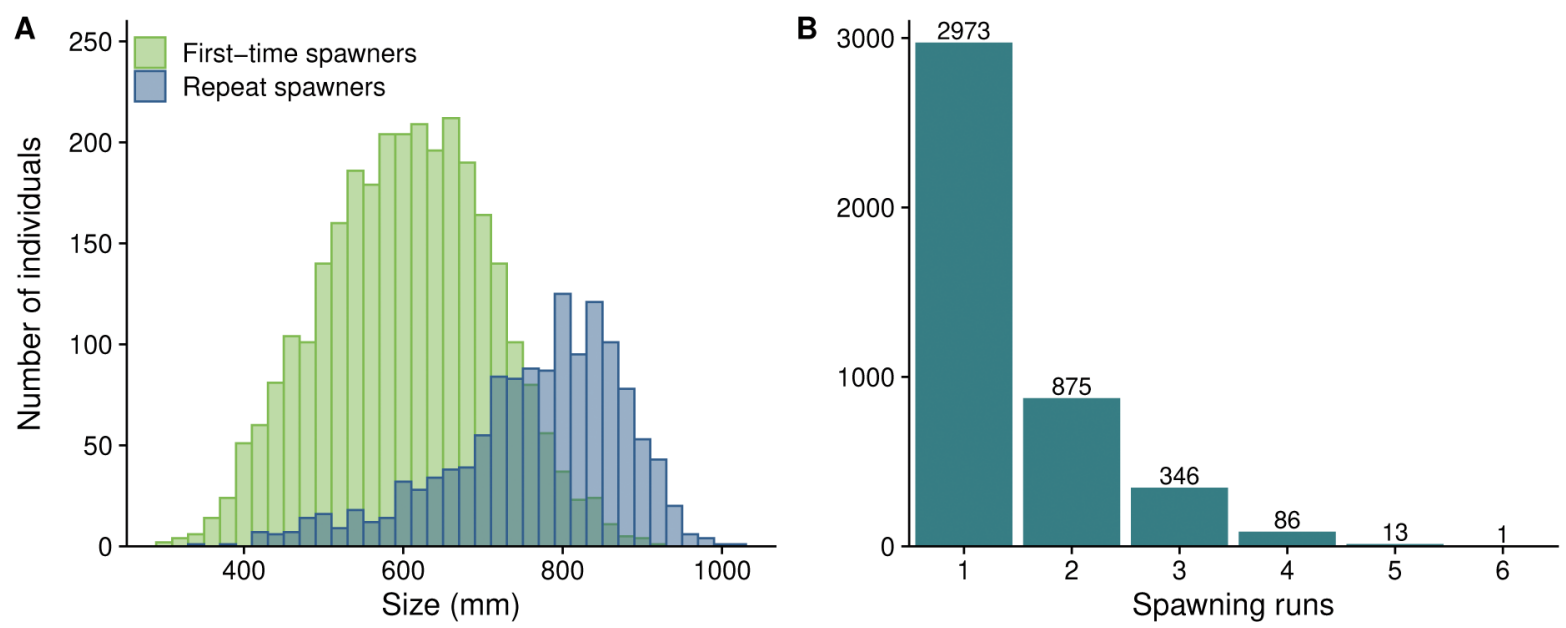

Fig. 3. (A) Distribution (bin width $=20 \mathrm{~mm}$ ) of spawners and (B) number of individuals with different total number of spawning runs in the data. Both panels show wild Hunder trout caught in the fish ladder 
Table 1. Overview of all transition kernels in the structured integral projection model for Hunder trout. See Tables $2 \& 3$ for details on the different parts of the kernels, and Fig. S6 in Supplement 1 for the life cycle with the dam

\begin{tabular}{|c|c|}
\hline Stage transition ( $j$ to $i)$ & Transition kernel \\
\hline Juvenile $\rightarrow$ Juvenile & $\begin{array}{l}K_{J, J, u}\left(x^{\prime}, x\right)=S_{j, u}(x)\left[1-P_{\text {smolt }}(x)\right] g_{R}\left(x^{\prime}, x\right) \\
K_{J, J, d}\left(x^{\prime}, x\right)=S_{j, d}(x)\left[1-P_{\text {smolt }}(x)\right] g_{R}\left(X^{\prime}, x\right)\end{array}$ \\
\hline Juvenile $\rightarrow$ Subadult & $\begin{array}{l}K_{J, S, u}\left(x^{\prime}, x\right)=S_{j, u}(x) P_{\text {smolt }}(x) S_{d a m}(x) g_{L}\left(x^{\prime}, x\right) \\
K_{J, S, d}\left(x^{\prime}, x\right)=S_{j, d}(x) P_{\text {smolt }}(x) g_{L}\left(x^{\prime}, x\right)\end{array}$ \\
\hline Subadult $\rightarrow$ Subadult & $K_{S, S}\left(x^{\prime}, x\right)=S_{S}(x)\left[1-P_{\text {mature }}(x)\right] g_{L}\left(x^{\prime}, x\right)$ \\
\hline Subadult $\rightarrow$ First-time spawner & $\begin{array}{l}K_{S, A 1, u}\left(x^{\prime}, X\right)=S_{s}(X) P_{\text {mature }}(X) g_{L}\left(X^{\prime}, X\right) P_{L}\left(x^{\prime}\right) \\
K_{S, A 1, d}\left(X^{\prime}, X\right)=S_{S}(X) P_{\text {mature }}(X) g_{L}\left(X^{\prime}, X\right)\left[1-P_{L}(X)\right]\end{array}$ \\
\hline First-time spawner $\rightarrow$ Juvenile & $\begin{array}{l}K_{A 1, J, u}\left(x^{\prime}, x\right)=q F(x) f(x) S_{0, u} \\
K_{A 1, J, d}\left(x^{\prime}, x\right)=q F(x) f\left(x^{\prime}\right) S_{0, d}\end{array}$ \\
\hline First-time spawner $\rightarrow$ Non-spawner & $\begin{array}{l}K_{A 1, A, u}\left(X^{\prime}, X\right)=S_{a, u}(x) g_{L}\left(x^{\prime}, X\right) \\
K_{A 1, A, d}\left(x^{\prime}, X\right)=S_{s}(X) g_{L}\left(X^{\prime}, X\right)\end{array}$ \\
\hline Non-spawner $\rightarrow$ Repeat spawner & $\begin{array}{l}K_{A, A 2+, u}\left(x^{\prime}, x\right)=S_{a, u}(x) g_{L}\left(x^{\prime}, x\right) P_{L}\left(x^{\prime}\right) \\
K_{A, A 2+, d}\left(x^{\prime}, x\right)=S_{a, d}(x) g_{L}\left(x^{\prime}, x\right)\left[1-P_{L}\left(x^{\prime}\right)\right]\end{array}$ \\
\hline Repeat spawner $\rightarrow$ Juvenile & $\begin{array}{l}K_{A 2+, J, u}\left(x^{\prime}, x\right)=q F(x) f\left(x^{\prime}\right) S_{0, u} \\
K_{A 2+, J, d}\left(x^{\prime}, x\right)=q F(x) f\left(x^{\prime}\right) S_{0, d}\end{array}$ \\
\hline Repeat spawner $\rightarrow$ Non-spawner & $\begin{array}{l}K_{A 2+, A, u}\left(X^{\prime}, X\right)=S_{a, u}(X) g_{L}\left(X^{\prime}, X\right) \\
K_{A 2+, A, d}\left(X^{\prime}, X\right)=S_{a, d}(X) g_{L}\left(X^{\prime}, X\right)\end{array}$ \\
\hline
\end{tabular}

and Section S1 in Supplement 1. All survival probabilities are expressed in terms of time-averaged mortality hazard rates (Ergon et al. 2018). All calculations and analyses were performed with $\mathrm{R}$ version 3.6.2 ( $\mathrm{R}$ Core Team 2019).

\subsection{Model scenarios}

To investigate the effect of spawning experience on the population dynamics of Hunder trout, we started with a baseline scenario without any harvesting or effect of spawning experience, to which results from perturbation scenarios were compared. For the different perturbation scenarios, we reduced the reproductive output of spawners by decreasing the early survival of their offspring from egg to age

Table 2 for variables used in the model). The size distribution was discretised using 300 size bins of $4.33 \mathrm{~mm}$, and to avoid unintentional eviction of large individuals in the model, we followed Williams et al. (2012) and expanded the upper size limit $U$ beyond the largest observed individual in our dataset (a $14 \mathrm{yr}$ old male at $1030 \mathrm{~mm}$ ). The final part in Eq. (1) is the size-and stage-structured kernels $K_{i, j, z}\left(x^{\prime}, x\right)$, which describe the location-specific transition from life stage $j$ in the current year $t$ (columns) to life stage $i$ in next year $t+1$ (rows) in a matrix of matrices (Matrix 1), $\mathbf{m}$ :

\begin{tabular}{|c|c|c|c|c|c|c|c|c|}
\hline & \multicolumn{8}{|c|}{ stage $j(t)$} \\
\hline & $J_{u}$ & $J_{d}$ & $S$ & $A_{1, u}$ & $A_{1, d}$ & $A$ & $A_{2+, u}$ & $A_{2+, d}$ \\
\hline$J_{u}$ & $K_{J, J, u}$ & 0 & 0 & $K_{A 1, J, u}$ & 0 & 0 & $K_{A 2+, J, u}$ & 0 \\
\hline$J_{d}$ & 0 & $K_{J, J, d}$ & 0 & 0 & $K_{A 1, J, d}$ & 0 & 0 & $K_{A 2+, J, d}$ \\
\hline$S$ & $K_{J, S, u}$ & $K_{J, S, d}$ & $K_{S, S}$ & 0 & 0 & 0 & 0 & 0 \\
\hline$A_{1, u}$ & 0 & 0 & $K_{S, A 1, u}$ & 0 & 0 & 0 & 0 & 0 \\
\hline$A_{1 d}$ & 0 & 0 & $K_{S, A 1 d}$ & 0 & 0 & 0 & 0 & 0 \\
\hline$A$ & 0 & 0 & 0 & $K_{A 1, A, u}$ & $K_{A 1, A, d}$ & 0 & $K_{A 2+, A, u}$ & $K_{A 2+, A, d}$ \\
\hline$A_{2+, u}$ & 0 & 0 & 0 & 0 & 0 & $K_{A, A 2+, u}$ & 0 & 0 \\
\hline$A_{2+, d}$ & 0 & 0 & 0 & 0 & 0 & $K_{A, A 2+, d}$ & 0 & 0 \\
\hline
\end{tabular}

where $J$ refers to juveniles in the river, $S$ to subadults in the lake, $A 1$ to first-time spawners (in the river), $A$ to non-spawning adults (in the lake, resting year), and $A 2+$ to repeat spawners (in the river). The kernels in matrix $\mathbf{m}$ are size-dependent, stage-and location-specific (Nater et al. 2021), and are given in Table 1. Descriptions of the variables are given in Table 2 and the vital rates are provided in Table 3
$1\left(S_{0, z}\right)$ up to an extreme scenario, whereby none of the juveniles survives. We decreased early survival, as it is expected to vary with maternal spawning experience (e.g. Jonsson 1985) and with various environmental climatic drivers (e.g. Elliott 1994) in brown trout. In the first and non-selective perturbation scenario, we decreased the reproductive output of all spawners in the population. In the second and selective perturbation scenario, we only decreased the reproductive output of the first-time spawners in the population. In a third perturbation scenario, only the reproductive output of repeat spawners was decreased. The results from the third pertubation scenario are not presented, as they were nearly indistinguishable from the first and non-selective perturbation scenario. For all perturbation scenarios, early survival was decreased by gradually increasing the early mortality hazard rate $\left(m_{j, z i}\right.$ Table 3$)$.

As harvesting is an important driver of population dynamics in Hunder trout (Aass \& Kraabøl 1999, Nater et al. 2021), we ran the perturbation scenarios with different levels of harvest mortality. The estimated harvest mortality hazard rate is size-dependent $m^{H}(x)$, and we increased the harvest intensity from no harvest as in the baseline scenario, up to the harvest level observed in the study system. For all scenarios, we calculated the asymptotic long-term population growth rate $(\lambda$, i.e. the dominant right eigenvalue of the projection matrix, Caswell 2001), which can be used as a proxy for population viability. We also calculated the stable size-by-stage distribu- 
Table 2. Variables used in the structured integral projection model for Hunder trout

\begin{tabular}{ll} 
Variable & Description \\
\hline$t$ & Time step (year) \\
$x$ & Size (mm) at time $t$ \\
$x^{\prime}$ & Size $(\mathrm{mm})$ at time $t+1$ \\
$q$ & Sex ratio at birth $(0.5)$ \\
$i, j$ & Life stages ${ }^{\mathrm{a}}$ individuals transition from $j$ to $i$ \\
$\Omega$ & Total number of life stages \\
$L, U$ & Lower and upper limits of the size range $(\mathrm{mm})_{i}$ \\
& $L=0, U=1300$ \\
$u, d, z$ & Position in river relative to the dam; \\
& $\quad u=$ upriver, $d=$ downriver, $z=$ either \\
${ }^{a}$ All life stages and transitions are listed in Table 1 \\
\end{tabular}

tion and thus the proportion of first-time to repeat spawners for the populations at equilibrium. The results from the perturbation scenarios were compared to the baseline scenario and each other to evaluate the effect of breeding experience on the population dynamics.

\section{RESULTS}

In the baseline scenario without decreased reproductive outputs and without harvesting, the longterm population growth rate is $\lambda=1.046$ (bottom left corners in Fig. 4). The stable distribution of the base- line scenario indicates that approximately a third of the spawners are first-timers, and approximately two-thirds are repeat spawners (Fig. S8A). Although the size distributions of the different spawner types overlap (Fig. 5A), repeat spawners are generally larger, and they produce three-quarters of the total number of juveniles age 1 in the population each year, most of them below the dam (Fig. S8B).

From the results of the perturbation scenarios, it is clear that both decreased reproductive output and harvest intensity have substantial and interactive effects on $\lambda$ (Fig. 4). In the first and non-selective perturbation scenario, $\lambda$ decreases as a result of the reduced reproductive output of all spawners (lefthand side of Fig. 4A). Under the most drastic decrease of reproductive output, i.e. no juveniles are produced in the population, $\lambda=0.388$ (top left corner in Fig. 4A), which is a $62.9 \%$ reduction from the baseline scenario (bottom left corner in Fig. 4A). In this extreme case, the population consists of nonspawning adults and repeat spawners, as these individuals have relatively low mortality compared to other life stages and will accumulate in the terminal stage, and no new individuals enter the population (Fig. 5B). The accumulation of older age classes is also present in classical age structured models with a terminal class when $\lambda$ is $<1$ (Caswell 2001). The effect of increasing harvest mortality on $\lambda$ of decreasing reproduction of all spawners is much larger than the effect through added harvest intensity (Fig. 4A).

Table 3. Summary of vital rates used in the integral projection model for Hunder trout. All survival probabilities are defined from time-averaged mortality hazard rates, and $z$ denotes the location relative to the dam

\begin{tabular}{|c|c|c|}
\hline Model component & Vital rate & Description \\
\hline Reproduction & $\begin{array}{l}F(x) \\
S_{0, z} \\
m_{0, z} \\
f\left(x^{\prime}\right)\end{array}$ & $\begin{array}{l}\text { Fecundity of adults of size } x \text { (number of eggs) } \\
\text { Early (egg to age 1) survival probability in location } z_{i}=\exp \left[-m_{0, z}\right] \\
\text { Early (egg to age 1) mortality hazard rate in location } z \\
\text { Size distribution of offspring in autumn }\end{array}$ \\
\hline Growth & $\begin{array}{l}g_{R}\left(x^{\prime}, x\right) \\
g_{L}\left(x^{\prime}, x\right)\end{array}$ & $\begin{array}{l}\text { Distribution of juveniles grown from size } x \text { to size } x^{\prime} \text { in the river } \\
\text { Distribution of subadults and adults grown from size } x \text { to size } x^{\prime} \text { in the lake }\end{array}$ \\
\hline $\begin{array}{l}\text { Pre-growth stage } \\
\text { transition }\end{array}$ & $\begin{array}{c}P_{\text {smolt }}(x) \\
P_{\text {mature }}(X)\end{array}$ & $\begin{array}{l}\text { Smolting probability of juveniles of size } x \\
\text { Maturation probability of subadults of size } x\end{array}$ \\
\hline $\begin{array}{l}\text { Post-growth stage } \\
\text { transition }\end{array}$ & $P_{L}\left(x^{\prime}\right)$ & Ladder usage probability of subadults and adults grown to size $x^{\prime}$ \\
\hline Survival & $\begin{array}{l}S_{j, z}(x) \\
m_{j, z}(x) \\
S_{\mathrm{dam}}(x) \\
m_{\mathrm{dam}}(x) \\
S_{S}(x) \\
m^{H}(x) \\
m_{s}^{\circ}(x) \\
S_{a, z}(x) \\
m_{a, z}^{\circ}(x)\end{array}$ & $\begin{array}{l}\text { Survival probability of juveniles of size } x \text { in location } z_{i}=\exp \left[-m_{j, z}(x)\right] \\
\text { Mortality hazard rate of juveniles of size } x \text { in location } z \\
\text { Dam survival probability of smolts of size } x_{i}=\exp \left[-m_{\mathrm{dam}}(x)\right] \\
\text { Dam mortality hazard rate of smolts of size } x \\
\text { Survival probability of subadults of size } x_{i}=\exp \left[-\left(m^{H}(x)+m_{s}^{\circ}(x)\right)\right] \\
\text { Harvest mortality hazard rate of subadults and adults of size } x \\
\text { Background mortality hazard rate of subadults of size } x \\
\text { Survival probability of adults of size } x \text { spawning in location } z_{i}=\exp \left[-\left(m^{H}(x)+m_{a, z}^{\circ}(x)\right)\right] \\
\text { Background mortality hazard rate of adults of size } x \text { spawning in location } z\end{array}$ \\
\hline
\end{tabular}


A

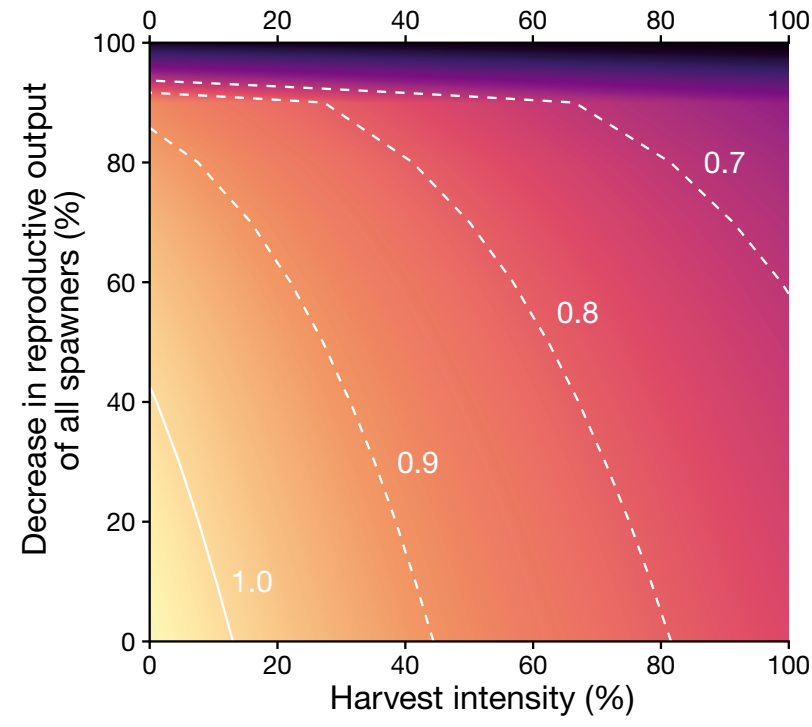

B

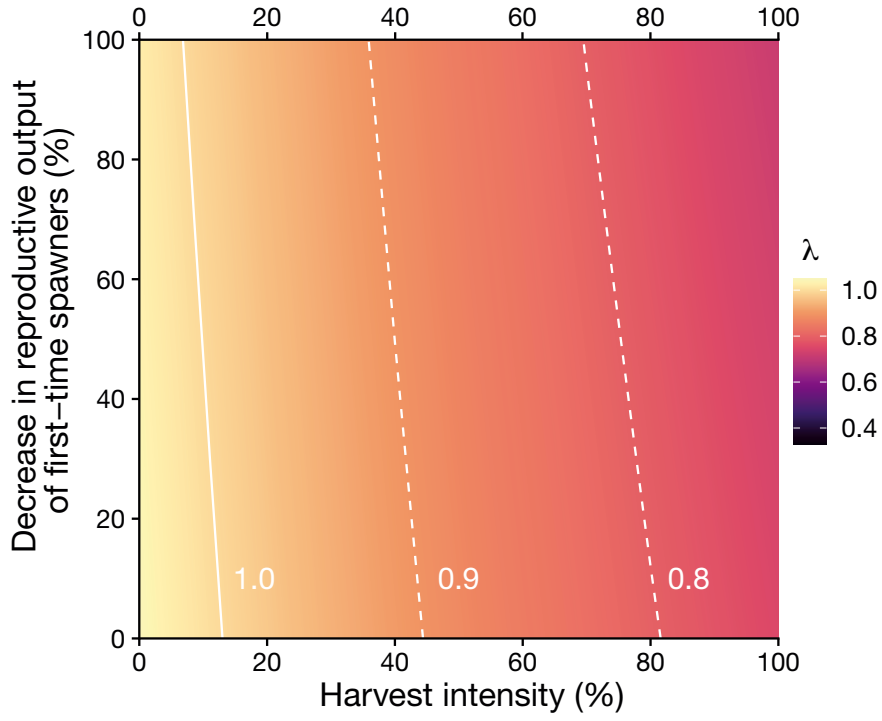

Fig. 4. Long-term population growth rate $(\lambda)$ calculated in model simulations for different levels of harvest intensity and decrease in reproductive output for (A) all spawners and (B) only first-time spawners. In both panels, the solid contour lines are $\lambda=1$, while the dashed lines are $\lambda=0.9,0.8$, and 0.7

A

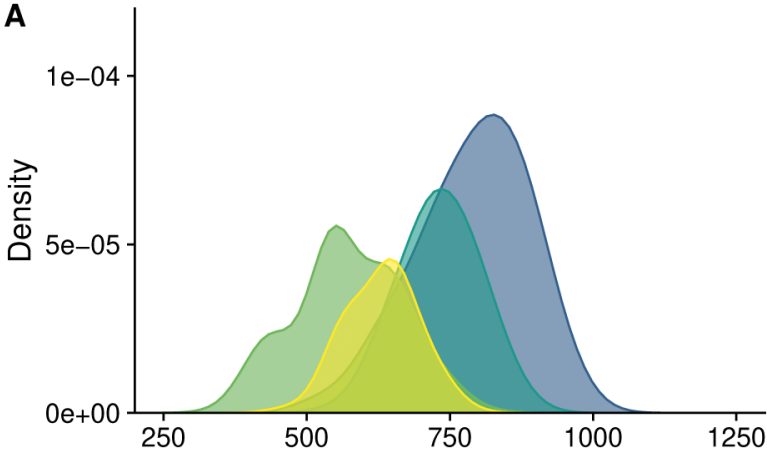

C

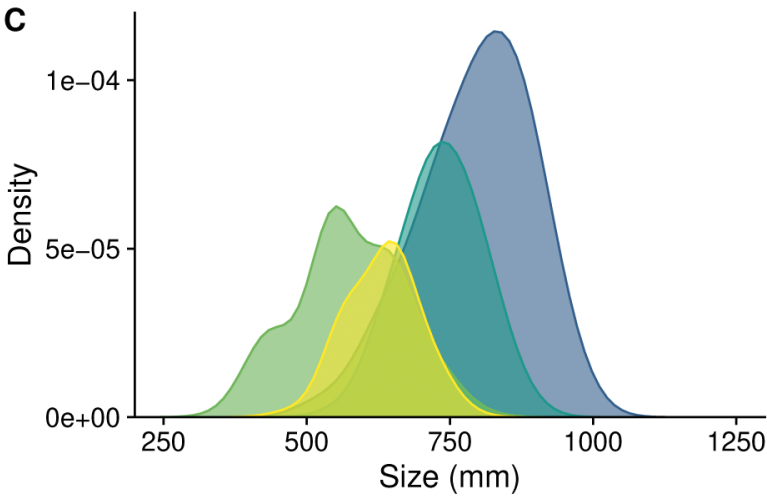

B

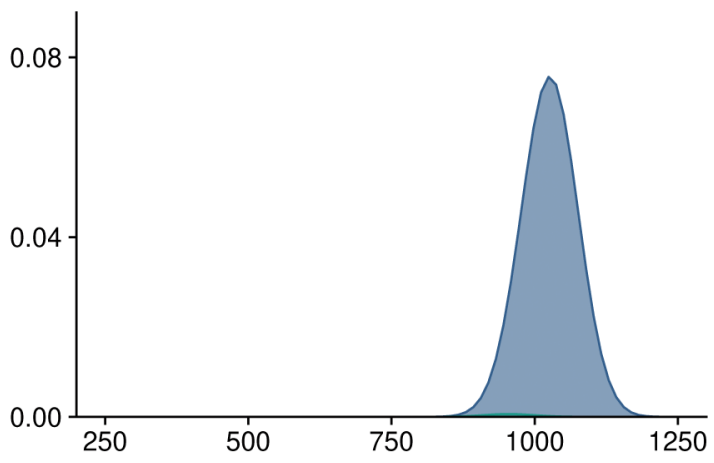

D

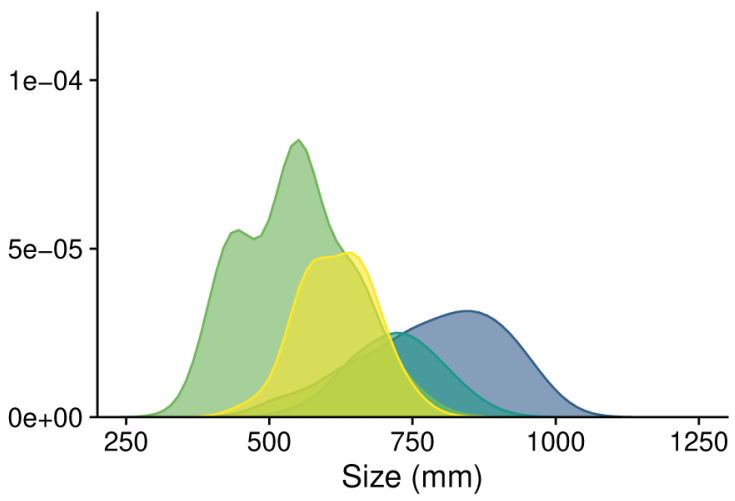

Repeat spawner (above) Repeat spawner (below)

Fig. 5. Stable size distributions of the 4 spawner stages in (A) the baseline scenario $(\lambda=1.046)$, (B) without reproductive output from any spawners $(\lambda=0.388),(C)$ without reproductive output from first-time spawners $(\lambda=1.025)$, and (D) at the harvest intensity observed in the study population $(\lambda=0.757)$, which is similar to the observed data in Fig. $3 \mathrm{~A}$. Above and below refer to the spawners' position in the river relative to the dam. Distributions are scaled to sum to 1 for the entire population for each panel, and the scale of the $y$-axis varies between panels 
In the second and selective perturbation scenario, when we reduce the reproductive output of only firsttime spawners, the stable size-by-stage distribution (Fig. 5C) is very similar to the baseline distribution (Fig. 5A). Additionally, under the most extreme decrease of reproductive output, i.e. when first-time spawners produce no juveniles, $\lambda=1.025$ (top left corner in Fig. 4B), which is a $2.0 \%$ reduction from the baseline scenario (bottom left corner in Fig. 4B). The effect of increasing harvest mortality on $\lambda$ is larger than the effect of reducing the reproduction of firsttime spawners (Fig. 4B). For the highest harvest intensity considered in the perturbation scenarios, i.e. the harvest mortality estimated for the study population, $\lambda=0.757$, which is a reduction of $27.6 \%$ from the baseline scenario (bottom right corners in Fig. 4). The harvest mainly targets the larger repeat spawners and decreases their density (Fig. 5D), and the distribution is very similar to the distribution of spawners caught in the ladder (Fig. 3A).

\section{DISCUSSION}

Our results indicate that for Hunder trout, the reproductive output of repeat spawners is more important for long-term population growth than that of first-time spawners. Reducing the reproductive output of first-time spawners had a relatively small effect on both the stable size distribution of the spawners and the long-term population growth rate $(\lambda)$ compared to when the reproductive output of all spawners was reduced. Moreover, the survival of first-time spawners to become repeat spawners seems more important for the population dynamics than their reproductive contribution.

Reducing the reproductive output of first-time spawners in the selective perturbation scenario, even to the extreme of suppressing it altogether, had very little impact on either population structure (Fig. 5C) or the long-term population growth rate (Fig. 4B) compared to the baseline scenario. This strongly supports the hypothesis that first-time spawners are less important than repeat spawners for the long-term population dynamics of Hunder trout. When reducing the reproductive output of all spawners in the non-selective perturbation scenario, $\lambda$ decreased slowly before it plummeted (Fig. 4A). The results of both perturbation scenarios indicate that the reproductive contribution of repeat spawners is very important for the long-term growth.

The model prediction that first-time spawner reproduction is less important than that of repeat spawners for the long-term growth of the Hunder trout population concurs with previous studies on iteroparous fish (e.g. Hislop 1988, Kjesbu et al. 1996, Óskarsson \& Taggart 2010). Several factors can contribute to why the reproductive output of repeat spawners is more important for the population, and in species with indeterminate growth, such as brown trout, the most obvious is body size. Both egg number and egg size tend to increase with female size (Jonsson 1978, L'Abee-Lund \& Hindar 1990, Jonsson \& Jonsson 1999), and while egg number correlates directly with fecundity, egg size correlates with fertility through quality, here expressed by early survival. Larger eggs typically have higher fertilisation and hatching probability (Jonsson 1985, Daniel et al. 1993, Evans et al. 1996, Kjesbu et al. 1996, Trippel 1998), lower egg mortality (Solemdal et al. 1995), larger larvae with higher growth rate (Monteleone \& Houde 1990), and higher early survival (Berkeley et al. 2004). Moreover, body size is often related to social status and dominance, which in turn correlates with mate and breeding site quality. In brown trout, males fight each other for access to nest-digging females, and females fight each other over nest sites, resulting in larger individuals of both sexes securing high-quality mates and nest locations (Jonsson \& Jonsson 2011, Esteve 2017).

Although body size is important for reproductive output, and repeat spawners are generally larger, individual variation in growth and age at maturation results in overlapping size distributions of first-time and repeat spawners (Figs. 3A \& 5). In addition, repeat spawners invest more energy in reproduction than first-time spawners when controlling for body size and energy consumption (e.g. Jonsson 1985, Berg et al. 1998, Berkeley et al. 2004). The correlations between female size, experience, and egg number and egg quality are likely the main contributors to why the reproduction of repeat spawners is more important for the long-term population growth rate in Hunder trout. Additional factors that can explain differences in reproductive output of spawners with different experience can be behavioural rather than physical. For instance, repeat spawners often have better timing of spawning, and it is believed to reduce the mismatch between hatching and larval food availability in spring (Kjesbu et al. 1996, Óskarsson \& Taggart 2010). In Hunder trout, older and likely repeat spawning females arrive first at the spawning grounds (Jensen \& Aass 1995). This might possibly improve their timing compared to first-time spawners in hatching date, but also in choice of high-quality nest sites 
and reduced density at the spawning ground and less intrasexual fighting.

Salmonids express a variety of life histories and reproductive strategies (Hendry \& Stearns 2004), and iteroparity can be viewed as a bet-hedging strategy to decrease the risk of lifetime reproductive failure (Bordeleau et al. 2020). Especially in varying environments, iteroparity can decrease extinction risk by increasing genetic diversity and dampen population fluctuations (Jonsson \& Jonsson 2011, Serbezov et al. 2012). Although repeat-spawning brown trout females invest more in reproduction and have lower survival than first-time spawning females (Berg et al. 1998), they increase their lifetime reproductive success by $38-52 \%$ relative to females that only spawn once (Serbezov et al. 2012). In many harvested salmonid populations, including the Hunder trout, there are generally fewer repeat than first-time spawners (Fleming 1998). Even though they are fewer, repeat spawners have a considerable positive influence on the population (Lawrence et al. 2016). The ratio of first-time to repeat spawners in a population is therefore suggested as a proxy for sustainability (Vasilakopoulos et al. 2011). The presence of repeat spawners at the spawning ground indicates less inbreeding, as several cohorts are intermixing (Jokikokko \& Jutila 2005), and an increase in the ratio of repeat to firsttime spawners signifies not only decreased homogeneity but also decreased probability of extinction (as observed in steelhead trout Oncorhynchus mykiss; Moore et al. 2014). Conversely, a decrease in the ratio of repeat to first-time spawners is often accompanied by shifts in population structure and life history towards fewer, shorter, and younger individuals at the spawning ground (observed in anadromous alewife Alosa pseudoharengus; Davis \& Schultz 2009). Shifts in the demographic structure towards smaller females can be linked to an overall reduced reproductive potential of the population (e.g. Ohlberger et al. 2020). In harvested populations, restoration of population structure to a pre-exploited one can help increase and maintain productivity (e.g. Richards \& Rago 1999, Edwards \& Plagányi 2011).

Many population models assume that all mature individuals either contribute equally to the reproductive output, or according to their size. Our model development offers an approach to explicitly include the effect of breeding experience at the population level. The more variable the reproductive biology of the species is, e.g. variation in recruitment, maturity, or sex ratio, the more detailed the model must be to provide precise estimates of reproductive output (e.g. Murawski et al. 2001, Marshall 2009, Morgan et al. 2011, Shelton et al. 2012). Our results highlight the importance of including traits that can affect the long-term growth rate of the population, such as breeding experience and its effect on early survival. When estimating reproductive output in iteroparous species, the contribution of first-time spawners should be investigated, and if applicable, disregarded or penalised to avoid overestimation (e.g. Óskarsson \& Taggart 2010). Few attempts have been made to quantify the contribution and importance of spawners with different experience on population dynamics in salmonids (Bordeleau et al. 2020, but see Lawrence et al. 2016). Here we have demonstrated that for Hunder trout, the reproductive contribution of firsttime spawners has little impact at the population level, and ignoring spawning experience and its effect on early survival could potentially give an overly optimistic estimate of the population productivity.

As distinct life stages influence the population differently, harvested populations should be managed so that their natural age and stage structure is maintained (Zhou et al. 2010). One strategy is the spawn-at-least-once principle, where fish only become vulnerable to fishing gear after they have spawned (Myers \& Mertz 1998), and immature individuals are protected from harvesting (Vasilakopoulos et al. 2011). Protecting immature fish can indeed prevent overfishing (Johnston et al. 2007, Edwards \& Plagányi 2011), but as in our case where the reproductive output of first-time spawners is less important than that of repeat spawners, a spawn-atleast-twice policy could be advantageous. Protecting juveniles and first-time spawners from harvest so that they can become repeat spawners (Edwards \& Plagányi 2011), and allowing the repeat spawners to reproduce before they are harvested, is likely to improve population stability and resilience to changes (Jokikokko \& Jutila 2005, Froese et al. 2008). In our study system, fishing could be restricted to increase first-time spawner survival, and/or limited to late or after the spawning season to allow the repeat spawners to reproduce. See Nater et al. (2021) for the effect of different size-limits and harvest scenarios on the population.

Brown trout is an important species for many fisheries, and has the longest recorded management history of all freshwater fish (Young et al. 2017). Freshwater ecosystems are concurrently among the most diverse and most threatened ecosystems in the world (He et al. 2019), and climate change is ranked as one of the world's greatest challenges for sustainable fisheries and aquaculture (FAO 2020). The 2 most common factors of climate change that affect 
freshwater species with river habitats are temperature and water flow, also known as river discharge (Rand et al. 2006). Salmonid and river management have always been closely related (Young et al. 2017), as salmonids generally rely on functional river systems to complete their life cycle, and many rivers are regulated, e.g. with dams. Dams are barriers that impede migration (Wheaton et al. 2004), and although fishways are common, they are recurrently suboptimal (Katopodis \& Williams 2012) as in our study system. As for other salmonid populations (e.g. Lawrence et al. 2016), the hydropower dam at Hunderfossen is likely to have a negative impact on the Hunder trout population, both as a migration barrier and by impairing the below-dam spawning grounds (Aass et al. 1989). Since the fish ladder is selective for intermediate sized fish, many of the large and fecund repeat spawners cannot ascend (Fig. 5), but are left to spawn at the diminished downriver spawning grounds. To investigate, we ran the perturbation scenarios with a below-dam spawner penalty. The penalty was applied by doubling the early mortality of their offspring, as in Nater et al. (2021). Predictably, when penalising the reproduction of belowdam spawners, $\lambda$ overall decreased (Fig. S7), but otherwise our results were not affected. Possible mitigation efforts include altering the river bed and increasing water flow below the dam, but it might also be possible to improve the fish ladder so that more repeat spawners can access the above-dam spawning grounds. The design success of fish ladders depends on both biology and hydraulics, and as climate change alters water flow, fishways must be adapted to maintain future functionality (Silva et al. 2018).

In Hunder trout, neither temperature nor discharge explain much of the observed variation in somatic growth for juveniles in the river (Nater et al. 2018). This concurs with a review on climatic variation and trout where these factors rarely correlated with growth (see Fig. 3 in Kovach et al. 2016). Although it is unclear why neither temperature nor discharge have had an effect on somatic growth in the Hunder trout population over the last $50 \mathrm{yr}$, there are some potential explanatory factors in our study system. Firstly, the river Gudbrandsdalslågen is fed by glacial meltwater and keeps a relatively low temperature all year round. Secondly, the river has been regulated since the 1960s by 2 hydropower dams that strongly control discharge and dampen flooding (Aass et al. 1989). The drastic reduction in water flow below the Hunderfossen dam, located in the middle of the main spawning area, is likely to affect the Hun- der trout population more strongly than potential climate-driven changes in discharge. In the lake, both air and surface temperature have large annual variations, but have steadily increased in the last century, especially the last decades (Hobæk et al. 2012). Despite increasing temperatures, and in contrast with other temperate lakes, there are no indications of an earlier onset of summer stratification in the lake (Hobæk et al. 2012). The cold Gudbrandsdalslågen is the main inlet river, and likely has a cooling effect on Lake Mjøsa. Additionally, the lake is large and deep, and water temperature decreases with depth. Like many other fish species, brown trout regulate body temperature by vertical movement in the water column (Jonsson \& Jonsson 2011).

Models are useful tools, as they can simulate the effect of different scenarios without threat to the actual population. There is always a trade-off between simplicity and realism; the model should be easy to use and interpret, but also capture the population dynamics. Realism can be increased by including population structure, and here we used a size-, stage-, and location-structured model. Many salmonid populations are regulated by early life density dependence (e.g. Einum \& Fleming 2000, Johnston et al. 2007). Density dependence is likely relevant for Hunder trout as well, especially below the dam where crowding is more likely. As we lack data on early life history in this system, we did not include density dependence, and the results should thus be interpreted qualitatively rather than quantitatively. Further investigations into the early life of Hunder trout might improve the model and our assessment of the population, especially how it is impacted by the dam. We made the simplifying assumption of female dominance, although if the harvest is male-biased, it could potentially cause the population to decline (Milner-Gulland et al. 2003, Stubberud et al. 2019), but we do not expect this to be a major issue in this system. Although our model is partly based on literature values (Nater et al. 2021), and a lot of the data come from fish ascending the size-selective ladder (Aass et al. 2017, Moe et al. 2020), we believe it includes the most essential aspects relevant for describing long-term dynamics, and how these dynamics depend on spawning experience.

While this study mainly focussed on long-term population growth rate, which is only one of many properties of population dynamics, other population parameters might be more sensitive to the reproduction of first-time spawners. Particularly short-term population dynamics could be sensitive to the reproductive output of first-time spawners, i.e. through 
the effect of strong cohorts where first-time spawners constitute a larger portion of the spawners. Potential developments of the model could therefore be to look at transient dynamics. It might also be possible to investigate meta-population dynamics, or selective pressures of different harvest strategies, for instance on age or size at maturity, or investment in reproduction if the probability of becoming a repeat spawner is affected.

Our results demonstrate how including spawning experience can inform assessment of population viability. Specifically, we found that increasing the reproductive success of repeat spawners and the survival of first-time spawners might be necessary for the continued existence of Hunder trout, and this insight can be useful in management of other iteroparous populations. Especially in variable environments, diversity in life history and reproductive strategy might reduce extinction risk, and we argue that it is important to restore and maintain a natural size and stage structure to uphold the productivity of the population. This is but one of many ways in which structured population models can guide and improve management and conservation effort.

Data accessibility. The individual-based long-term data from the study population are available in the Dryad Digital Repository (https://doi.org/10.5061/dryad.9cnp5hqf4, Nater et al. 2020a) and documented in the data paper by Moe et al. (2020). The code needed to build the IPM is provided in Supplement 2 at www.int-res.com/articles/ suppl/cr01645_supp2.pdf.

Acknowledgements. This work was supported by the Research Council of Norway, project SUSTAIN (244647/E10). We thank all who have been involved in collecting, maintaining, and organising the Hunder trout data. We also thank 3 reviewers who provided helpful comments.

\section{LITERATURE CITED}

Aass P (1993) Stocking strategy for the rehabilitation of a regulated brown trout (Salmo trutta L.) river. Regul Rivers Res Manag 8:135-144

Aass P, Kraabøl M (1999) The exploitation of a migrating brown trout (Salmo trutta L.) population; change of fishing methods due to river regulation. Regul Rivers Res Manag 15:211-219

Aass P, Nielsen PS, Brabrand $\AA$ (1989) Effects of river regulation on the structure of a fast-growing brown trout (Salmo trutta L.) population. Regul Rivers Res Manage 3:255-266

Aass P, Rustadbakken A, Moe SJ, Lund E, Qvenild T (2017) Life-history data on Hunder brown trout (Salmo trutta) from Lake Mjøsa, Norway. Freshw Metadata J 25:1-11

Arnekleiv JV, Kraabøl M, Museth J (2007) Efforts to aid downstream migrating brown trout (Salmo trutta L.) kelts and smolts passing a hydroelectric dam and a spillway. In: Almeida PR, Quintella BR, Costa MJ, Moore A (eds) Developments in fish telemetry. Springer, Dordrecht, p 5-15

* Berg OK, Thronæs E, Bremset G (1998) Energetics and survival of virgin and repeat spawning brown trout (Salmo trutta). Can J Fish Aquat Sci 55:47-53

Berkeley SA, Chapman C, Sogard SM (2004) Maternal age as a determinant of larval growth and survival in a marine fish, Sebastes melanops. Ecology 85:1258-1264

Bordeleau X, Pardo SA, Chaput G, April J and others (2020) Spatio-temporal trends in the importance of iteroparity across Atlantic salmon populations of the northwest Atlantic. ICES J Mar Sci 77:326-344

Carr JP, Kaufman L (2009) Estimating the importance of maternal age, size, and spawning experience to recruitment of Atlantic cod (Gadus morhua). Biol Conserv 142:477-487

Caswell H (2001) Matrix population models: construction, analysis, and interpretation. Sinauer Associates, Sunderland, MA

Curio E (1983) Why do young birds reproduce less well. Ibis 125:400-404

* Daniel ES, Parrish CC, Somerton DC \& Brown JA (1993) Lipids in eggs from first-time and repeat spawning Atlantic halibut, Hippoglossus hippoglossus (L.). Aquacult Res 24:187-191

*Davis JP, Schultz ET (2009) Temporal shifts in demography and life history of an anadromous alewife population in Connecticut. Mar Coast Fish 1:90-106

Easterling MR, Ellner SP, Dixon PM (2000) Size-specific sensitivity: applying a new structured population model. Ecology 81:694-708

*Edwards CTT, Plagányi ÉE (2011) Protecting old fish through spatial management: Is there a benefit for sustainable exploitation? J Appl Ecol 48:853-863

*Einum S, Fleming IA (2000) Selection against late emergence and small offspring in Atlantic salmon (Salmo salar). Evolution 54:628-639

Elliott JM (1994) Quantitative ecology and the brown trout. Oxford University Press, Oxford

Ellner SP, Rees M (2006) Integral projection models for species with complex demography. Am Nat 167:410-428

Engen S, Lande R, Sæther BE, Gienapp P (2010) Estimating the ratio of effective to actual size of an age-structured population from individual demographic data. J Evol Biol 23:1148-1158

Ergon T, Borgan Ø, Nater CR, Vindenes Y (2018) The utility of mortality hazard rates in population analyses. Methods Ecol Evol 9:2046-2056

Esteve M (2017) The velocity of love. The role of female choice in salmonine reproduction. In: Lobón-Cerviá J, Sanz N (eds) Brown trout. John Wiley \& Sons, Chichester, p 145-163

Evans RP, Parrish CC, Brown JA, Davis PJ (1996) Biochemical composition of eggs from repeat and first-time spawning captive Atlantic halibut (Hippoglossus hippoglossus). Aquaculture 139:139-149

FAO (2020) The state of world fisheries and aquaculture 2020. Sustainability in action. Food and Agriculture Organization of the United Nations, Rome

Fleming IA (1998) Pattern and variability in the breeding system of Atlantic salmon (Salmo salar), with comparisons to other salmonids. Can J Fish Aquat Sci 55:59-76

Froese R, Stern-Pirlot A, Winker H, Gascuel D (2008) Size matters: how single-species management can contribute to ecosystem-based fisheries management. Fish Res 92: 231-241 
Greeley JR (1932) The spawning habits of brook, brown and rainbow trout, and the problem of egg predators. Trans Am Fish Soc 62:239-248

Harnish RA, Sharma R, McMichael GA, Langshaw RB, Pearsons TN (2014) Effect of hydroelectric dam operations on the freshwater productivity of a Columbia River fall chinook salmon population. Can J Fish Aquat Sci 71:602-615

Haugen TO, Aass P, Stenseth NC, Vøllestad LA (2008) Changes in selection and evolutionary responses in migratory brown trout following the construction of a fish ladder. Evol Appl 1:319-335

*He F, Zarfl C, Bremerich V, David JNW and others (2019) The global decline of freshwater megafauna. Glob Change Biol 25:3883-3892

Hendry AP, Stearns SC (eds) (2004) Evolution illuminated: salmon and their relatives. Oxford University Press, New York, NY

Hislop JRG (1988) The influence of maternal length and age on the size and weight of the eggs and the relative fecundity of the haddock, Melanogrammus aeglefinus, in British waters. J Fish Biol 32:923-930

* Hobæk A, Løvik JE, Rohrlack T, Moe SJ and others (2012) Eutrophication, recovery and temperature in Lake Mjøsa: detecting trends with monitoring data and sediment records. Freshw Biol 57:1998-2014

Huitfeldt-Kaas H (1916) Mjøsens fisker og fiskeries. K Norske Vidensk Selskaps Skr 2:1-257

Jensen AJ, Aass P (1995) Migration of a fast-growing population of brown trout (Salmo trutta L.) through a fish ladder in relation to water flow and water temperature. Regul Rivers Res Manage 10:217-228

Johnston FD, Post JR, Mushens CJ, Stelfox JD, Paul AJ, Lajeunesse B (2007) The demography of recovery of an overexploited bull trout, Salvelinus confluentus, population. Can J Fish Aquat Sci 64:113-126

Jokikokko E, Jutila E (2005) Effect of fishing regulation on the occurrence of repeat spawners and age distribution of Atlantic salmon in a northern Baltic river. Fish Manag Ecol 12:341-347

Jonsson B (1978) Demographic strategy in a brown trout population in western Norway. Zool Scr 6:255-263

* Jonsson B (1985) Life history patterns of freshwater resident and sea-run migrant brown trout in Norway. Trans Am Fish Soc 114:182-194

Jonsson B, Jonsson N (2011) Ecology of Atlantic salmon and brown trout. Habitat as a template for life histories. Springer Netherlands, Dordrecht

Jonsson N, Jonsson B (1999) Trade-off between egg mass and egg number in brown trout. J Fish Biol 55:767-783

Katopodis C, Williams JG (2012) The development of fish passage research in a historical context. Ecol Eng 48: 8-18

Kjesbu OS, Solemdal P, Bratland P, Fonn M (1996) Variation in annual egg production in individual captive Atlantic cod (Gadus morhua). Can J Fish Aquat Sci 53:610-620

Knell RJ, Martínez-Ruiz C (2017) Selective harvest focused on sexual signal traits can lead to extinction under directional environmental change. Proc R Soc B 284:20171788

Komdeur J (1996) Influence of helping and breeding experience on reproductive performance in the Seychelles warbler: a translocation experiment. Behav Ecol 7:326-333

Kovach RP, Muhlfeld CC, Al-Chokhachy R, Dunham JB, Letcher BH, Kershner JL (2016) Impacts of climatic variation on trout: a global synthesis and path forward. Rev Fish Biol Fish 26:135-151
Künkele J (2000) Does primiparity affect the efficiency of converting energy to offspring production in the guineapig? Can J Zool 78:300-306

L'Abee-Lund JH, Hindar K (1990) Interpopulation variation in reproductive traits of anadromous female brown trout, Salmo trutta L. J Fish Biol 37:755-763

Lawrence ER, Kuparinen A, Hutchings JA (2016) Influence of dams on population persistence in Atlantic salmon (Salmo salar). Can J Zool 94:329-338

Lobón-Cerviá J, Sanz N (eds) (2017) Brown trout. Biology, ecology and management. John Wiley \& Sons, Hoboken, NJ

Marshall CT (2009) Implementing information on stock reproductive potential in fisheries management: the motivation, challenges and opportunities. In: Jakobsen T, Fogarty MJ, Megrey BA, Moksness E (eds) Fish reproductive biology: implications for assessment and management. Wiley-Blackwell, Oxford, p 395-420

Marteinsdóttir G, Begg GA (2002) Essential relationships incorporating the influence of age, size and condition on variables required for estimation of reproductive potential in Atlantic cod Gadus morhua. Mar Ecol Prog Ser 235:235-256

Milner-Gulland EJ, Bukreeva OM, Coulson T, Lushchekina AA, Kholodova MV, Bekenov AB, Grachev IA (2003) Reproductive collapse in saiga antelope harems. Nature 422:135

*Moe SJ, Nater CR, Rustadbakken A, Vøllestad LA and others (2020) Long-term mark-recapture and growth data for large-sized migratory brown trout (Salmo trutta) from Lake Mjøsa, Norway. Biodivers Data J 8:e52157

Monteleone DM, Houde ED (1990) Influence of maternal size on survival and growth of striped bass Morone saxatilis Walbaum eggs and larvae. J Exp Mar Biol Ecol 140:1-11

* Moore JW, Yeakel JD, Peard D, Lough J, Beere M (2014) Life-history diversity and its importance to population stability and persistence of a migratory fish: steelhead in two large North American watersheds. J Anim Ecol 83: 1035-1046

*Morgan MJ, Perez-Rodriguez A, Saborido-Rey F (2011) Does increased information about reproductive potential result in better prediction of recruitment? Can J Fish Aquat Sci 68:1361-1368

*Muhlfeld CC, Dauwalter DC, Kovach RP, Kershner JL, Williams JE, Epifanio J (2018) Trout in hot water: a call for global action. Science 360:866-867

*Mumme RL, Schoech SJ, Woolfenden GE, Fitzpatrick JW (2000) Life and death in the fast lane: demographic consequences of road mortality in the Florida scrub-jay. Conserv Biol 14:501-512

*Murawski SA, Rago PJ, Trippel EA (2001) Impacts of demographic variation in spawning characteristics on reference points for fishery management. ICES J Mar Sci 58: 1002-1014

* Myers RA, Mertz G (1998) The limits of exploitation: a precautionary approach. Ecol Appl 8:S165-S169

Nater CR, Rustadbakken A, Ergon T, Langangen $\varnothing$ and others (2018) Individual heterogeneity and early life conditions shape growth in a freshwater top predator. Ecology 99:1011-1017

Nater CR, Moe SJ, Rustadbakken A, Vøllestad LA and others (2020a) Data from: Long-term mark-recapture and growth data for large-sized migratory brown trout (Salmo trutta) from Lake Mjøsa, Norway. Dryad, Dataset, Nater CR, Vindenes Y, Aass P, Cole D and others (2020b) 
Size- and stage-dependence in cause-specific mortality of migratory brown trout. J Anim Ecol 89:2112-2133

Nater CR, Stubberud MW, Langangen $\varnothing$, Rustadbakken A and others (2021) Towards a future without stocking: harvest and river regulation determine long-term population viability of migratory salmonids. Clim Res, doi: $10.3354 / \mathrm{cr} 01644$

Ohlberger J, Schindler DE, Brown RJ, Harding JM and others (2020) The reproductive value of large females: consequences of shifts in demographic structure for population reproductive potential in chinook salmon. Can J Fish Aquat Sci 77:1292-1301

Potts GR, Coulson JC, Deans IR (1980) Population dynamics and breeding success of the shag, Phalacrocorax aristotelis, on the Farne islands, Northumberland. The J Anim Ecol 49:465-484

Óskarsson GJ, Taggart CT (2010) Variation in reproductive potential and influence on Icelandic herring recruitment. Fish Oceanogr 19:412-426

R Core Team (2019) R: a language and environment for statistical computing. R Foundation for Statistical Computing, Vienna

Rand PS, Hinch SG, Morrison J, Foreman MGG and others (2006) Effects of river discharge, temperature, and future climates on energetics and mortality of adult migrating Fraser River sockeye salmon. Trans Am Fish Soc 135: 655-667

Richards RA, Rago PJ (1999) A case history of effective fishery management: Chesapeake Bay striped bass. N Am J Fish Manag 19:356-375

Serbezov D, Jorde PE, Bernatchez L, Olsen EM, Vøllestad LA (2012) Life history and demographic determinants of effective/census size ratios as exemplified by brown trout (Salmo trutta). Evol Appl 5:607-618

Shelton AO, Munch SB, Keith D, Mangel M (2012) Maternal age, fecundity, egg quality, and recruitment: linking stock structure to recruitment using an age-structured Ricker model. Can J Fish Aquat Sci 69:1631-1641

Silva AT, Lucas MC, Castro-Santos T, Katopodis C and others (2018) The future of fish passage science, engineering, and practice. Fish Fish 19:340-362

Snowdon CT (1996) Infant care in cooperatively breeding species. Adv Stud Behav 25:643-689

Sogard SM, Berkeley SA, Fisher R (2008) Maternal effects in rockfishes Sebastes spp.: a comparison among species. Mar Ecol Prog Ser 360:227-236 DOI:

Editorial responsibility: Nils Bunnefeld (Guest Editor),

Stirling, UK

Reviewed by: 3 anonymous referees
Solemdal P, Kjesbu OS \& Fonn M (1995) Egg mortality in recruit-and repeat-spawning cod: an experimental study. ICES CM 1995/G:35

Stubberud MW, Vindenes Y, Vøllestad LA, Winfield IJ, Stenseth NC, Langangen $\varnothing$ (2019) Effects of size- and sex-selective harvesting: an integral projection model approach. Ecol Evol 9:12556-12570

Subbey S, Devine JA, Schaarschmidt U, Nash RDM (2014) Modelling and forecasting stock-recruitment: current and future perspectives. ICES J Mar Sci 71:2307-2322

Trippel EA (1998) Egg size and viability and seasonal offspring production of young Atlantic cod. Trans Am Fish Soc 127:339-359

*Vasilakopoulos P, O'Neill FG, Marshall CT (2011) Misspent youth: Does catching immature fish affect fisheries sustainability? ICES J Mar Sci 68:1525-1534

*Venturelli PA, Shuter BJ, Murphy CA (2009) Evidence for harvest-induced maternal influences on the reproductive rates of fish populations. Proc R Soc B 276:919-924

* Weimerskirch H, Jouventin P (1987) Population dynamics of the wandering albatross, Diomedea exulans, of the Crozet Islands: causes and consequences of the population decline. Oikos 49:315-322

Wheaton JM, Pasternack GB, Merz JE (2004) Spawning habitat rehabilitation. I. Conceptual approach and methods. Int J River Basin Manag 2:3-20

*Wigley SE (1999) Effects of first-time spawners on stockrecruitment relationships for two groundfish species. J Northwest Atl Fish Sci 25:215-218

Williams JL, Miller TEX, Ellner SP (2012) Avoiding unintentional eviction from integral projection models. Ecology 93:2008-2014

Woolfenden GE, Fitzpatrick JW (1984) The Florida scrub jay: demography of a cooperative-breeding bird. Princeton University Press, Princeton, NJ

Young KA, Gaskell P, Jacklin T, Williams JE (2017) Brown trout management for the 21st century. In: Lobón-Cerviá J, Sanz N (eds) Brown trout. John Wiley \& Sons, Chichester, p 735-769

Zedrosser A, Dahle B, Støen OG, Swenson JE (2009) The effects of primiparity on reproductive performance in the brown bear. Oecologia 160:847

* Zhou S, Smith ADM, Punt AE, Richardson AJ and others (2010) Ecosystem-based fisheries management requires a change to the selective fishing philosophy. Proc Natl Acad Sci USA 107:9485-9489

Submitted: August 20, 2020

Accepted: February 25, 2021

Proofs received from author(s): May 17, 2021 